\title{
Implementasi Sentiment Analysis Tanggapan Masyarakat Terhadap Pembangunan di Kota Pontianak
}

\author{
Lian Ardiani ${ }^{\text {a1 }}$, Herry Sujaini ${ }^{\mathrm{a} 2}$, Tursina ${ }^{\mathrm{a} 3}$ \\ a Jurusan Informatika Universitas Tanjungpura \\ Jl. Prof. Dr. H. Hadari Nawawi, Pontianak, Kalimantan Barat 78115 \\ ${ }^{1}$ lianardiani@gmail.com \\ ${ }^{2}$ hsduntan.ac.id \\ ${ }^{3}$ tursinalinformatika.untan.ac.id
}

\begin{abstract}
Abstrak
Sentiment analysis merupakan proses untuk memahami dan mengolah data tekstual secara otomatis untuk mendapatkan informasi sentimen yang terkandung dalam suatu kalimat opini. Pada umumnya masyarakat di zaman modern ini menuangkan dan mengekspresikan opininya ke media sosial terhadap berbagai topik, salah satu media sosial yang digunakan adalah twitter. Penelitian ini mencoba menganalisis tweet untuk dilakukan implementasi sentiment analysis terhadap opini masyarakat yang tertuang dalam twitter. Implementasi ini dilakukan dengan mengklasifikasikan tweet untuk mendapatkan informasi sentimen yang terkandung dalam tanggapan masyarakat, salah satu metode pengklasifikasian sentimen yaitu naïve bayes. Metode klasifikasi naïve bayes atau dikenal juga dengan teorema bayes memiliki ciri utama dalam asumsi opini yaitu menggunakan metode probabilitas dan statistik, teorema bayes menghitung nilai probabilitas tertinggi untuk klasifikasi sentimen. Jika suatu kata sering muncul dalam suatu dokumen maka diasumsikan bahwa kata tersebut merupakan kata penting dan diberikan nilai tertinggi, tapi jika kata muncul dalam berbagai dokumen maka kata tersebut bukanlah kata unik maka kata akan diberikan nilai rendah, dalam teorema bayes kata sendiri merupakan suatu unigrams dimana kata merupakan sentimen. Pengujian implementasi berbasis web menggunakan Bahasa Pemograman PHP menujukkan bahwa tweet dapat terklasifikasi secara otomatis. Data diklasifikasikan kedalam 3 (tiga) kelas yaitu, kelas positif, negatif dan netral. Proses dalam melakukan sentiment analysis dilakukan dengan melakukan text processing, setelah melewati tahapan text processing opini akan diklasifikasikan dengan metode klasifikasi naïve bayes ke dalam kelas positif, negatif atau netral. Secara keseluruhan hasil pengujian dengan menerapkan metode klasifikasi naïve bayes untuk mengolah informasi sentimen yang terdapat dalam suatu data tweet secara otomatis yang dikategorikan dalam tiga kelas yaitu positif, negatif dan netral dengan jumlah data latih sebesar 450 dan data uji sebesar 50, didapatkan akurasi sebesar $72 \%$.
\end{abstract}

Kata kunci: Sentiment analysis, naïve bayes, teorema bayes, twitter, opini.

\section{Implementation of Sentiment Analysis of Community Responses to Development in Pontianak City}

\begin{abstract}
Sentiment analysis is a process to understand and process textual data automatically to get sentiment information contained in an opinion sentence. In general, people in modern times pour and express their opinions on social media on various topics; one of the social media used is Twitter. This study tries to analyze the tweet to be carried out the implementation of sentiment analysis of public opinion contained in Twitter. This implementation is carried out by classifying tweets to get sentiment information listed in public responses; one of the methods of classifying sentiments is naïve Bayes. The naïve Bayes classification method, also known as the Bayes theorem, has the main character in opinion assumptions, namely using the probability and statistical purposes, the Bayes theorem calculates the highest probability value for sentiment classification. If a word often appears in a document, then it is assumed that the word is an important word and is given the highest value, but if the name appears in various documents, then the word is not unique then the name will be given a low cost, in Bayes theorem the word itself is a unigram where words are sentiments. Testing the web-based implementation using the PHP Programming Language shows that tweets can be classified automatically. The data is classified into 3 (three) classes, i.e., positive, negative, and neutral classes. The process of doing sentiment analysis is done by doing text processing; after passing through the text, processing opinion will be classified with the naïve
\end{abstract}


Bayes classification method into positive, negative, or neutral classes. Overall test results by applying the naïve Bayes classification method to process sentiment information contained in a tweet data automatically categorized into three categories, positive, negative and neutral with a total of 450 training data and test data of 50 , obtained an accuracy of 72\% .abstracts and keywords are made in two languages, Indonesian and English. Title letters use Times New Roman size 18. Abstract letters use Cambia Math, size ten and have a maximum of 300 words. The title and content of the abstract must provide the reader with information about the main content of the paper being written. The abstract content briefly describes the problem, objectives, methods/models used, results, and conclusions resulting from the research conducted. Abstracts may not contain pictures, equations, or library references. Avoid writing abbreviations without explanation. Keyword letters use Cambia Math size 10, which includes a maximum of six keywords. Keywords can be words or pairs of words that can describe the paper written.

Keywords: Sentiment analysis, naïve bayes, bayes theorem , twitter, opinion.

\section{Pendahuluan}

Informasi saat ini sangat mudah diperoleh dan dibagikan, karena begitu cepat perkembangan internet dengan adanya media sosial seperti salah satunya yaitu twitter yang memberikan kemudahan akses bagi pengguna internet untuk membagikan informasi dan membahas serta menuangkan opini terhadap berbagai topik. Opini yang tertulis pada media sosial mayoritas berupa data tekstual, opini tersebut dapat bersifat positif, negatif ataupun netral. Untuk mendapatkan informasi sentimen yang terkandung dalam opini tersebut maka dilakukanlah suatu analisis untuk mengevaluasi dan menilai data tekstual tersebut sehingga dapat menjadi sebuah informasi yang berharga, pengolahan analisis ini dikenal dalam dunia pemrosesan teks dengan sentiment analysis. Sentiment analysis merupakan proses untuk memahami dan mengolah data tekstual secara otomatis untuk mendapatkan informasi sentimen yang terkandung dalam suatu kalimat opini [1]. Penelitian di bidang sentiment analysis atau yang dikenal dengan opinion mining mulai marak dilakukan pada tahun 2002. Sentiment analysis acap kali digunakan untuk menilai suatu produk. Opinion mining bisa dianggap sebagai kombinasi antara text mining dan natural language processing [2].

Penelitian ini mencoba untuk mengklasifikasikan tanggapan atau sentimen masyarakat yang penerapannya terhadap pembangunan di Kota Pontianak. Banyak tantangan di dalam sentiment analysis salah satunya bagaimana menentukan suatu tweet bersentimen positif, negatif atau netral. Kedua adalah banyaknya pengguna internet dalam mengekspresikan opininya dengan gaya bahasa yang berbeda-beda dalam menulis tweet. Klasifikasi opini menjadi hal yang tidak mudah dimana juga pengguna twitter hanya dapat menulis postingan secara singkat karena jumlah penulisan karakter twitter dibatasi, sehingga terdapat banyaknya data tweet yang terdapat kalimat dengan kosakata dan tata bahasa yang tidak baku. Kemudian bagaimana suatu kalimat opini dianggap bersifat positif dan sebaliknya bahwa suatu opini dianggap bersifat negatif [3]. Untuk mengurangi noise yang terdapat pada tweet, dilakukan sebuah proses yaitu text preprocessing, Dalam text processing dilakukan beberapa tahapan yaitu berupa case folding, tokenisasi, filtering, dan stemming. Setelah dilakukan tahapan text preprocessing, data tweet akan diklasifikasikan kedalam kelas sentimen dengan menggunakan metode klasifikasi naïve bayes.

\section{TINJAUAN PUSTAKA}

\section{A. Tanggapan dan Opini}

Menurut Kamus Besar Bahasa Indonesia (KBBI), tanggapan merupakan apa yang diterima oleh pancaindra, pendapat, pandangan, sambutan dan reaksi. Menurut Kamus Besar Bahasa Indonesia (KBBI) opini adalah pendapat; pikiran atau pandangan, dan opini menurut Webster's New Collegiate Dictionary adalah suatu pandangan, keputusan atau taksiran yang terbentuk di dalam pikiran mengenai suatu persoalan tertentu.

Jadi dapat disimpulkan bahwa dalam memberikan suatu reaksi terhadap apa yang telah diamati dan dilihat serta dirasakan dengan pancaindra diberikan tanggapan berupa pendapat atau opini dalam mengekspresikan buah pikiran mengenai persoalan tertentu.

\section{B. Sentiment Analysis}

Sentiment analysis atau opinion mining mengacu pada bidang yang luas dari pengolahan bahasa alami, komputasi linguistik dan text mining yang bertujuan menganalisa pendapat, sentimen, evaluasi, sikap, penilaian dan emosi seseorang apakah pembicara atau penulis berkenan dengan suatu topik, produk, layanan, organisasi, individu, ataupun kegiatan tertentu. Tugas dasar dalam sentiment analysis adalah mengelompokkan polaritas dari teks yang ada dalam dokumen, kalimat, atau fitur/tingkat aspek apakah pendapat yang dikemukakan dalam dokumen, kalimat atau fitur entitas/aspek bersifat positif, negatif, atau netral [4]. Jadi, sentiment analysis berfokus pada pengolahan opini yang mengandung polaritas, yaitu memiliki nilai sentimen positif, negatif atau netral.

Berdasarkan sumber datanya sentiment analysis terbagi menjadi 2 kelompok yaitu, coarse-grained sentiment analysis, sentiment analysis yang dilakukan pada level dokumen, secara garis besar fokus utama dari sentiment analysis jenis ini adalah menganggap seluruh isi dokumen sebagai sebuah sentimen positif dan sentimen negatif. Fined-grained sentiment analysis adalah sentiment analysis yang dilakukan pada level kalimat, fokus utamanya adalah menentukan sentimen pada setiap kalimat. Sentiment analysis dapat diklasifikasikan kedalam kelas sentimen bersifat positif, negatif dan netral [5].

1) Sentimen Positif: Menurut Kamus Besar Bahasa Indonesia (KBBI) sentimen positif merupakan reaksi atau sikap yang meningkatkan nilai seseorang atau sesuatu. 
Dari struktur kalimat dalam penelitian ini kalimat bersentimen positif sebagai contoh "Senang sekali dengan adanya beberapa taman dan ruang baca, semoga bisa membuat kota Pontianak lebih bersinar".

2) Sentimen Negatif: Menurut Kamus Besar Bahasa Indonesia (KBBI) sentimen negatif merupakan reaksi atau sikap yang menurunkan nilai seseorang atau sesuatu, jadi kalimat bersentimen negatif akan menyebabkan penyurutan nilai pandang terhadap sesuatu, sehingga membentuk tren down. Umumnya kalimat bersentimen negatif ditandai dengan penggunaan kata negasi. Negasi merupakan sesuatu yang dikenal dalam semua bahasa dan biasanya negasi digunakan untuk mengubah polaritas dari suatu pernyataan [6]. Dari struktur kalimat bersentimen negatif sebagai contoh "Rencana pemerintah merenovasi Taman Budaya Kalimantan Barat tak pernah terealisasi. Tak pernah di perbaiki sejak di bangun tahun $1982 \mathrm{cc}$ @BangMidji agar di perhatikan".

3) Sentimen Netral: Kata netral sendiri dalam Kamus Besar Bahasa Indonesia (KBBI) berarti tidak berpihak, kalimat bersentimen netral merupakan ekspresi kalimat yang tidak bersifat positif maupun negatif. Dari struktur kalimat bersentimen netral adalah sebagai berikut "Mengunjungi karnaval khatulistiwa di Pontianak \#KalbarMenangTotal".

\section{Text Preprocessing}

Text preprocessing merupakan tahap awal dimana data teks dengan noise akan dikurangi agar dapat diolah lebih lanjut, untuk mengurangi noise tersebut. Tahap text preprocessing ini mencakup semua rutinitas, dan proses untuk mempersiapkan data yang akan digunakan pada operasi knowledge discovery sistem text mining. Data tekstual akan diproses dalam beberapa tahapan text preprocessing yaitu case folding, tokenisasi, filtering dan stemming. Dengan dilakukannya text preprocessing akan terbentuk dataset bersih, dataset yang terbentuk dari proses ini akan memudahkan dalam pemrosesan sistem.

4) Case Folding: Case folding dilakukan untuk mengubah setiap karakter didalam teks menjadi huruf kecil. Tidak semua kata dalam teks konsisten dalam penggunaan huruf kapital disinilah tujuan dilakukan case folding untuk mengkonversi setiap karakter dalam kata menjadi huruf kecil [6].

5) Tokenisasi: Tokenisasi merupakan proses pemecahan kata pada suatu teks ke dalam satuan kata. Tokenisasi dilakukan untuk menghasilkan kumpulan kata yang berdiri sendiri, tokenisasi memecah teks yang semula berupa kalimat menjadi kata-kata. tokenisasi menghilangkan delimeter seperti titik (.), koma (,), spasi, dan karakter angka yang ada pada kata tersebut [7].

Dalam penelitian ini tokenisasi dilakukan untuk memecah kata, serta melakukan penghapusan delimeter beserta karakter angka bersama tweet entity seperti hashtag, retweet dan mention.

6) Filtering: Filtering merupakan proses dalam text preprocessing setelah tokenisasi, filtering dilakukan untuk untuk mengambil kata penting hasil tokenisasi. Pada tahap filtering kata akan ditentukan apakah akan digunakan atau dibuang. Proses dalam filtering dalam membuang katakata yang tidak digunakan atau stopword terdapat dalam bag of words stoplist [8].

Stopword merupakan daftar kata-kata yang tidak mempresentasikan isi dari suatu dokumen teks, stopword dilakukan untuk meghilangkan kata atau term yang tidak memiliki arti. Daftar stoplist akan dibuat sebelum melakukan proses stopword removal, jika kata-kata terdapat dalam daftar stoplist, maka kata tersebut akan dihapus, sehingga kata-kata yang tersisa akan dianggap kata yang mencirikan isi suatu dokumen.

7) Stemming: Stemming merupakan proses mengubah kata menjadi bentuk dasarnya. Stemming dilakukan untuk meyeragamkan bentuk kata. Tujuan dari proses stemming adalah menghilangkan imbuhan-imbuhan baik itu berupa prefiks, sufiks, maupun konfiks yang ada pada setiap kata [9]. Stemming dalam penelitian ini dilakukan berdasarkan aturan morfologi bahasa Indonesia.

\section{Klasifikasi}

Klasifikasi merupakan proses menentukan atau menilai suatu objek untuk memasukkannya ke kelas-kelas yang telah ditentukan. Klasifikasi teks dapat didefinisikan sebagai proses untuk menentukan suatu dokumen teks ke dalam suatu kelas tertentu [10]. Dalam penelitian ini klasifikasi dilakukan untuk memprediksi orientasi tweet kedalam kelas yang sudah ditentukan yaitu positif, negatif atau netral. Proses klasifikasi dalam sentiment analysis dapat dilakukan dengan berbagai algoritma, salah satunya yaitu naïve bayes.

Nä̈ve bayes merupakan salah satu metode yang digunakan pada text mining yang sederhana tetapi memiliki keakuratan yang tinggi dalam mengklasifikasi [11]. Nä̈ve bayes memiliki waktu klasifikasi yang singkat sehingga mempercepat proses sentiment analysis. Metode klasifikasi nä̈ve bayes merupakan metode klasifikasi berdasarkan probabilitas dan teorema bayes (aturan bayes) dengan asumsi indenpendensi yang kuat.

Dalam algoritma naïve bayes setiap dokumen dipresentasikan dengan pasangan atribut " $x_{1}, x_{2}, x_{3}, \ldots, x_{n}$ " dimana $x_{1}$ adalah kata pertama, $x_{2}$ adalah kata kedua dan seterusnya. Probabilitas dari semua dokumen (posterior probability) suatu dokumen pada suatu kategori dapat dihitung dengan menggunakan persamaan berikut [12],

$$
\mathrm{V}_{\text {MAP }}==_{V_{j} V}^{\arg \max } \frac{P\left(X_{1}, X_{2}, \ldots, X_{n} \mid V_{j}\right) P\left(V_{j}\right)}{P\left(X_{1}, X_{2}, \ldots, X_{n}\right)} \pi
$$

Klasifikasi teks menggunakan nä̈ve bayes dilakukan dengan memaksimalkan nilai dari persamaan, asumsi kemandirian bersyarat yang "naif" memegang peranan. Untuk penyebut $P\left(X_{1}, X_{2}, \ldots, X_{n} \mid V_{j}\right)$ nilainya konstan atau sama untuk semua kategori $\left(V_{j}\right)$. Sehingga persamaan dapat ditulis sebagai berikut,

$$
\mathrm{V}_{\text {MAP }}={ }_{V e V}^{\arg \max } P\left(X_{1}, X_{2}, \ldots, X_{n} \mid V_{j}\right) P\left(V_{j}\right)
$$


Persamaan diatas dapat disederhanakan menjadi,

$$
\mathrm{V}_{\text {MAP }}={ }_{V e V}^{\arg \max } \prod_{i=1}^{n} P\left(X_{i} \mid V_{j}\right) P\left(V_{j}\right)
$$

Keterangan:

$V_{j}=\quad$ Kategori tweet $j=1,2,3, \ldots \mathrm{n}$.

Dimana dalam penelitian ini $j_{1}=$ kategori tweet sentimen positif, $j_{2}=$ kategori tweet sentimen negatif, dan $j_{3}=$ kategori tweet sentimen netral.

$P\left(X_{i} \mid V_{j}\right) \quad=\quad$ Probabilitas $x_{i}$ pada kategori $V_{j}$. $P\left(V_{j}\right)=\quad$ Probabilitas dari $V_{j}$.

Untuk nilai dan dihitung pada saat pelatihan dimana persamaannya adalah sebagai berikut:

$$
\begin{aligned}
& P\left(V_{j}\right)=\frac{\mid \text { docs } j \mid}{\mid \text { contoh } \mid} \\
& P\left(X_{i} \mid V_{j}\right)=\frac{n_{k}+1}{n+\mid \text { kosakata } \mid}
\end{aligned}
$$

Keterangan:

$|\operatorname{docs} j|=$ Jumlah dokumen setiap

kategori $j$.

$\mid$ contoh $\mid=$ Jumlah dokumen dari semua kategori.

$n_{k}=$ Jumlah frekuensi kemunculan kata, untuk

menghindari nilai 0 maka pembilang ditambahkan 1 .

$n=$ Jumlah frekuensi kemunculan kata dari setiap kategori.

$\mid$ kosakata $\mid=$ Jumlah semua kata dari semua kategori.

Ringkasan dari algoritma dengan metode klasifikasi naïve bayes adalah sebagai berikut [13]:

1. Proses pelatihan. Input adalah data yang sudah diketahui kategorinya

a. $\mid$ kosakata $\mid \leftarrow$ himpunan semua kata yang unik dari dokumen-dokumen

b. Untuk setiap kategori $V_{j}$ lakukan :

- $\quad \mid$ docs $j \mid \leftarrow$ himpunan dokumen-dokumen yang berada pada kategori $V_{j}$.

- $\quad$ Hitung $P\left(V_{j}\right)$.

- Untuk setiap $x_{i}$ pada $\mid$ kosakata $\mid$ lakukan: 1.Hitung $P\left(X_{i} \mid V_{j}\right)$.

2. Proses Klasifikasi. Input adalah dokumen yang belum diketahui kategorinya

a. Hasilkan $\mathrm{V}_{\mathrm{MAP}}$ dengan menggunakan $P\left(X_{i} \mid V_{j}\right)$ dan $P\left(V_{j}\right)$ yang telah diperoleh dari pelatihan.

\section{E. Dataset}

Dataset yang akan digunakan berasal dari media sosial twitter berupa tweet sebagai data tekstual. Dataset merupakan kumpulan data latih dan data uji, dari data ini akan dihitung akurasi berdasarkan persentase jumlah data latih dan data uji. Tahap pertama adalah melakukan pelatihan terhadap data opini yang telah diketahui kategorinya, dan tahap kedua adalah proses klasifikasi dokumen yang belum diketahui kategorinya. Dataset yang digunakan berfokus pada tweet berbahasa Indonesia yang membahas tentang pembangunan di Kota Pontianak.

\section{F. Recall dan Precission}

Recall dan precision digunakan untuk mengukur efektivitas sistem temu kembali informasi. Nilai dari recall dan precission biasanya ditunjukan dalam persen (\%).

$$
\begin{aligned}
& \text { Recall }=\frac{\text { jumlah dokumen relevan yang terpanggil }(\mathrm{a})}{\text { jumlah dokumen relevan yang ada di dalam database }(\mathrm{a}+\mathrm{c})} \times 100 \\
& \text { Precision }=\frac{\text { jumlah dokumen relevan yang terpanggil }(\mathrm{a})}{\text { jumlah dokumen yang terpanggil dalam pencarian }(\mathrm{a}+\mathrm{b})} \times 100
\end{aligned}
$$

TABEL I

TABEL RELEVANSI

\begin{tabular}{|c|c|c|c|}
\hline & Relevant & Not Relevant & Total \\
\hline Retrieved & $\mathrm{a}$ (hits) & $\mathrm{b}$ (noise) & $\mathrm{a}+\mathrm{b}$ \\
\hline Not Retrieved & $\mathrm{c}$ (misses) & $\mathrm{d}$ (reject) & $\mathrm{c}+\mathrm{d}$ \\
\hline Total & $\mathrm{a}+\mathrm{c}$ & $\mathrm{b}+\mathrm{d}$ & $\mathrm{a}+\mathrm{b}+\mathrm{c}+\mathrm{d}$ \\
\hline
\end{tabular}

Keterangan:

a (hits) : $\quad$ Dokumen yang relevan.

b (noise) : $\quad$ Dokumen yang tidak relevan.

c (misses) : Dokumen relevan yang tidak

ditemukan.

$\mathrm{d}$ (reject) : Dokumen tidak relevan yang tidak ditemukan.

\section{Metodologi PENELITIAN}

Sentiment analysis merupakan salah satu cabang penelitian text mining. Secara khusus tujuan text mining dapat dibagi menjadi dua yaitu pengkategorisasian data teks (text categorization) dan pengelompokkan data teks (text clustering). Dalam pengkategorisasian, text mining dipergunakan sebagai alat untuk menemukan kategori yang sesuai dengan kelas yang ditentukan (supervised learning), sedangkan pengelompokkan dalam text mining berfungsi sebagai alat untuk mengelompokkan data teks berdasarkan kesamaan karakteristik, dan clustering dapat digunakan untuk memberikan label pada kelas yang belum diketahui (unsupervised learning) [14]. Tujuan utama pada penelitian ini adalah pengkategorisasian teks (text categorization), karena penelitian ini melakukan pengkategorian sebuah tweet apakah bersentimen positif, negatif atau netral.

\section{Pengumpulan Data}

Data yang digunakan dalam penelitian ini berupa tanggapan masyarakat mengenai pembangunan Kota Pontianak. Data dibagi menjadi data latih dan data uji. Proses pembuatan dataset didapatkan dari data yang telah diambil dari media sosial twitter berupa tweets, data berupa data tekstual. Data yang diterima kemudian akan dibuat data latih dan data ujinya, dimana data latih merupakan data yang telah diketahui kategorinya, sedangkan data uji merupakan data yang belum diketahui kategorinya. Data latih sendiri merupakan kumpulan data yang telah dibagi sesuai dengan kategorinya secara manual, masing-masing data latih akan dibagi ke dalam kelas sentimen positif, negatif dan netral. 


\section{Perancangan dan Pembuatan Sentiment Analysis}

Pada proses ini akan dilakukan dalam 2 tahapan:

8) Text preprocessing: merupakan tahap dimana teks akan diseragamkan bentuk katanya agar dapat dipersiapkan menjadi data yang akan diolah selanjutnya. Tahapan text preprocessing meliputi case folding, tokenisasi, filtering dan stemming. Gambar.1 menunjukkan tahapan pada text preprocessing.

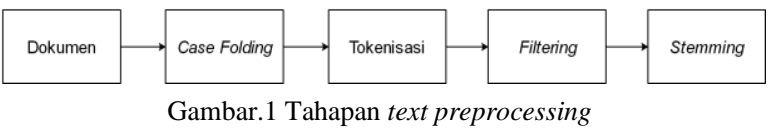

Case Folding adalah proses penyeragaman dengan mengubah semua huruf dalam dokumen menjadi huruf kecil. Tokenisasi dalam penelitian ini merupakan tahapan dalam memecah string atau input terhadap suatu teks berdasarkan tiap kata yang menyusunnya dan menghilangkan URL, @mention dan hashtag yang ada pada dokumen (tweets) beserta menghilangkan delimeterdelimeter seperti tanda titik (.), koma (,), spasi dan karakter angka dan tanda baca yang ada pada dokumen (tweets). Filtering yaitu tahap mengambil kata-kata penting dari hasil tokenisasi atau merupakan tahap menghilangkan kata-kata yang tidak mengandung makna. Filtering dapat dilakukan dengan menghilangkan stopwords. Stemming merupakan pemetaan kata menjadi bentuk kata dasarnya.

9) Proses klasifikasi: dalam penelitian ini menggunakan metode klasifikasi naïve bayes.

\section{E. Arsitektur Sistem}

Sistem yang dibangun adalah sistem yang dapat digunakan dalam melakukan sentiment analysis pada tanggapan masyarakat terhadap pembangunan di Kota Pontianak pada twitter. Sistem bekerja dengan melakukan crawling tweet dengan memanfaatkan twitter API, yang nantinya akan diproses oleh sistem untuk mendapatkan nilai sentimen yang terdapat dalam tweet dengan melewati tahapan text preprocessing, kemudian setelah itu akan dilakukan klasifikasi sentimen untuk mendapatkan hasil klasifikasinya. Adapun diagram arsitektur sistem pada Gambar.2.

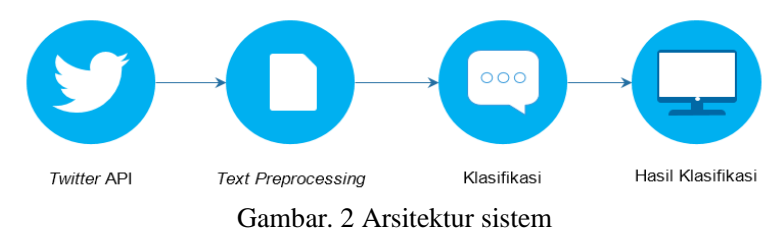

\section{HASIL PENELITIAN}

\section{A. Pengumpulan Dataset}

Data berupa tweet yang berhubungan dengan kota Pontianak yang terkait dengan penelitian yang dilakukan. Proses pengumpulan data yang dilakukan dengan melakukan crawling manual pada twitter search, dari hasil yang didapatkan dataset yang digunakan berjumlah 500 tweets. Setelah dataset dibangun, masing-masing akan dibagi menjadi dua yaitu data uji dan data latih, dimana data latih dilakukan pengelompokkan menjadi 3 (tiga) kelas untuk dilabel sesuai jenis sentimen mana yang merupakan tweet bersentimen positif, negatif atau netral. Masing-masing berjumlah 150 data per kategori kelas data latih dan 50 data digunakan sebagai data uji dapat dilihat pada Tabel 2 .

TABEL II

RINCIAN DATASET

\begin{tabular}{|c|c|}
\hline Jenis Sentimen $\boldsymbol{T w e e t}$ & Jumlah \\
\hline Latih & 450 \\
\hline Uji & 50 \\
\hline Total Dataset & 500 \\
\hline
\end{tabular}

Contoh dataset yang dikumpulkan pada Gambar.3.

Hari ini kekantor @BPJSTKinfo Pelayanan cepat petugasnya ramah dan ruangan dingin, meskipun cuaca pontianak panas. \#Pontianak @BPJSTK_Mobile

Gambar. 3 Contoh tweet

\section{B. Labelling}

Setelah dataset telah terpenuhi, langkah selanjutnya melakukan pelabelan pada setiap tweets tersebut. Proses pelabelan dilakukan dengan memilih orientasi data dari tweet apakah positif, negatif dan netral. Pelabelan data tweet dilakukan secara manual. Pelabelan dilakukan untuk membentuk data latih, dan dilakukan juga pelabelan pada data uji untuk menghitung akurasi dari hasil sentimen yang didapat secara otomatis.

\section{Text Preprocessing}

1) Case Folding: Proses case folding dilakukan untuk mengubah semua huruf dalam dokumen menjadi huruf kecil. Gambar.4 merupakan proses case folding yang dilakukan.

hari ini kekantor @bpjstkinfo pelayanan cepat petugasnya ramah dan ruangan dingin, meskipun cuaca pontianak panas.

Gambar. 4 Hasil tweet melewati tahapan case folding

2) Tokenisasi: Dari hasil tokenisasi kalimat yang sudah dipecah menjadi kata akan dimasukkan ke dalam array. Tabel 3 merupakan proses hasil tokenisasi yang telah dilakukan.

TABEL III

HASIL TWEET MELEWATI TAHAPAN TOKENISASI

\begin{tabular}{|l|l|l|l|l|}
\hline hari & ini & kekantor & pelayanan & cepat \\
\hline petugasnya & ramah & dan & ruangan & dingin \\
\hline meskipun & cuaca & pontianak & panas & \\
\hline
\end{tabular}

3) Filtering: Filtering dilakukan untuk membersihkan kata-kata hasil tokenisasi dengan penggunaan stopwords removal. Pada penelitian ini stoplist disesuaikan dengan tweet text. Proses filtering yang dilakukan ditunjukkan pada Tabel 4. 
TABEL IV

HASIL TWEET MELEWATI TAHAPAN FILTERING

\begin{tabular}{|l|l|l|l|l|}
\hline hari & kekantor & pelayanan & cepat & petugasnya \\
\hline ramah & ruangan & dingin & cuaca & pontianak \\
\hline panas & & & & \\
\hline
\end{tabular}

4) Stemming: Tahapan dari proses stemming yang dilakukan dengan menggunakan algoritma Arifin dan Setiono. Tahapan dari proses stemming dengan algoritma Arifin dan Setiono adalah sebagai berikut [15]:

a. Pemeriksaan semua kemungkinan bentuk kata. Setiap kata diasumsikan memiliki 2 awalan (prefiks) dan 3 akhiran (sufiks).

\section{Prefiks $1+$ Prefiks $2+$ Kata dasar + Sufiks $3+$}

\section{Sufiks $2+$ Sufiks 1}

Jika dalam kata yang diperiksa tidak memiliki imbuhan sebanyak imbuhan seperti formula di atas, maka imbuhan yang kosong atau tidak ada tersebut diberi tanda $\mathrm{x}$ untuk prefiks dan diberi tanda xx untuk sufiks.

b. Pemotongan dalam Algoritma ini dilakukan secara berurutan sebagai berikut:
AW : AW (Awalan)
AK : AK (Akhiran)
KD : KD (Kata Dasar)

- AW I, hasilnya disimpan pada pe1 (prefiks 1)

- AW II, hasilnya disimpan pada pe2 (prefiks2)

- AK I, hasilnya disimpan pada su1 (sufiks 1)

- AK II, hasilnya disimpan pada su2 (sufiks 2)

- AK III, hasilnya disimpan pada su3 (sufiks 3)

Pada setiap tahap pemotongan di atas diikuti dengan pemeriksaan di kamus apakah hasil pemotongan itu sudah berada dalam bentuk dasar. Kalau pemeriksaan ini berhasil maka proses dinyatakan selesai dan tidak perlu melanjutkan proses pemotongan imbuhan lainnya.

c. Akan tetapi, apabila sampai pada pemotongan AK III, belum ditemukan dalam kamus, maka akan dilakukan proses kombinasi. Kata dasar yang dihasilkan dikombinasikan dengan imbuhan-imbuhannya dalam 12 konfigurasi berikut:

- KD

- $\mathrm{KD}+\mathrm{AK}$ III

- $\mathrm{KD}+\mathrm{AK}$ III + AK II

- $\mathrm{KD}+\mathrm{AK} I I I+\mathrm{AK} I I+\mathrm{AK} I$

- $\mathrm{AW} \mathrm{I}+\mathrm{AW} \mathrm{II}+\mathrm{KD}$

- $\mathrm{AW} \mathrm{I}+\mathrm{AW}$ II + KD + AK III

- $\mathrm{AW} \mathrm{I}+\mathrm{AW} \mathrm{II}+\mathrm{KD}+\mathrm{AK} \mathrm{III}+\mathrm{AK} I \mathrm{II}$

- $\mathrm{AW} \mathrm{I}+\mathrm{AW} I \mathrm{II}+\mathrm{KD}+\mathrm{AK} \mathrm{III}+\mathrm{AK} \mathrm{II}+\mathrm{AK}$ I

- $\mathrm{AW}$ II + KD

- $\mathrm{AW} \mathrm{II} \mathrm{+} \mathrm{KD} \mathrm{+} \mathrm{AK} \mathrm{III}$

- $\mathrm{AW} I \mathrm{II}+\mathrm{KD}+\mathrm{AK}$ III + AK II

- $\mathrm{AW} \mathrm{II} \mathrm{+} \mathrm{KD} \mathrm{+} \mathrm{AK} \mathrm{III} \mathrm{+} \mathrm{AK} \mathrm{II} \mathrm{+} \mathrm{AK} \mathrm{I}$

Sebenarnya kombinasi a, b, c, d, h, dan 1 sudah diperiksa pada tahap sebelumnya, karena kombinasi ini adalah hasil pemotongan bertahap tersebut. Dengan demikian, kombinasi yang masih perlu dilakukan tinggal 6 yakni pada kombinasikombinasi yang belum dilakukan (e, f, g, i, j, dan k). Tentunya bila hasil pemeriksaan suatu kombinasi adalah 'ada', maka pemeriksaan pada kombinasi lainnya sudah tidak diperlukan lagi. Pemeriksaan 12 kombinasi ini diperlukan, karena adanya fenomena overstemming pada algoritma pemotongan imbuhan. Kelemahan ini berakibat pada pemotongan bagian kata yang sebenarnya adalah milik kata dasar itu sendiri yang kebetulan mirip dengan salah satu jenis imbuhan yang ada. Dengan 12 kombinasi itu, pemotongan yang sudah terlanjur tersebut dapat dikembalikan sesuai posisinya.

Setelah tahapan filtering akan dilakukan stemming, tahapan akhir dari text preprocessing dan setelah stemming data tweet akan diolah ke tahapan selanjutnya. Stemming yang dilakukan ditunjukkan pada Tabel 5.

TABEL V

HASIL TWEET MELEWATI TAHAPAN STEMMING

\begin{tabular}{|l|l|l|l|l|}
\hline hari & kantor & layan & cepat & petugas \\
\hline ramah & ruang & dingin & cuaca & pontianak \\
\hline panas & & & & \\
\hline
\end{tabular}

\section{Pengujian}

Pengujian yang dilakukan dengan membuat sistem berbasis web yang memanfaatkan twitter API yang berfungsi untuk mengambil data tweet secara terkini untuk dilakukan pengklasifikasian secara langsung ke dalam kategori kelas sentimen yang telah ditentukan yaitu positif, negatif dan netral. Proses klasifikasi menggunakan metode naïve bayes. Pemanfaatan twitter API dengan menggunakan sampel pencarian “@bangmidji” dengan hasil yang didapat pada Gambar 5.

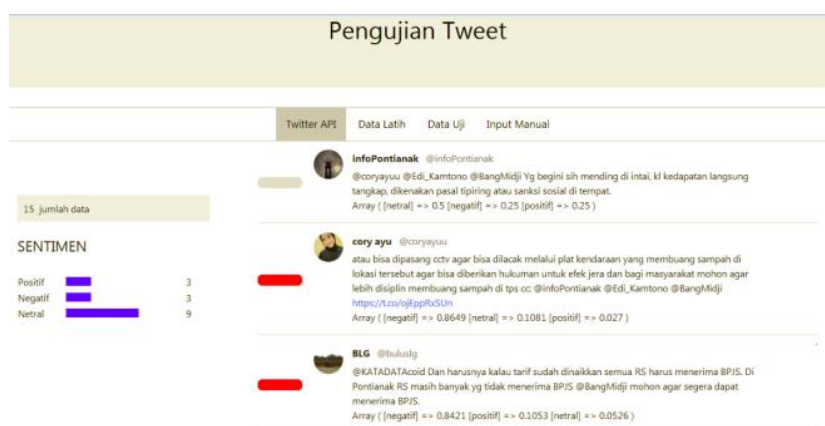

Gambar. 5 Hasil pengujian tweet dengan menggunakan twitter API

Twitter API membatasi pengambilan data tweet sesuai dengan ketentuan pada halaman tentang standard API twitter yang bisa dilihat pada sumber dari situs twitter (https://developer.twitter.com/en/docs/tweets/search/apireference/get-search-tweets.html). Dimana ketentuan pada pengambilan tweets dengan memanfaatkan standard twitter API dibatasi hanya 15 tweets selama 7 hari kebelakang 
Pada penelitian ini juga dilakukan pengujian terhadap klasifikasi sentimen yang telah dilakukan. Perbandingan dataset yang dilakukan yaitu data latih 450 dan data uji 50 dengan metode klasikasi naïve bayes. dengan skenario yang dapat dilihat pada Tabel 6 .

TABEL VI

TABEL SKENARIO DATASET

\begin{tabular}{|l|c|c|c|}
\hline \multicolumn{1}{|c|}{ Data } & Positif & Negatif & Netral \\
\hline Latih & 150 & 150 & 150 \\
\hline Uji & 17 & 17 & 16 \\
\hline TOTAL & \multicolumn{3}{|c|}{500} \\
\hline
\end{tabular}

Tweet pada data uji akan diprediksi oleh aplikasi pengujian yang telah dibuat, untuk melakukan pengecekan akurasi. Data uji sebelumnya telah telah dikategorikan secara manual ke dalam kelas-kelas yang telah ditentukan lalu akan dicek akurasinya. Tabel 7 menunjukkan data uji yang akan diklasifikasi untuk dihitung akurasinya.

TABEL VII

DATA UJI

\begin{tabular}{|l|l|c|c|c|c|}
\hline \multicolumn{2}{|c|}{ DATA UJI } & \multicolumn{3}{|c|}{ Prediksi } & \multirow{2}{*}{ Total } \\
\cline { 3 - 6 } \multicolumn{2}{|c|}{} & Negatif & Positif & Netral & \\
\hline \multirow{3}{*}{$\begin{array}{l}\text { Label } \\
\text { Manual }\end{array}$} & Negatif & 12 & 1 & 4 & 17 \\
\cline { 2 - 6 } & Positif & 1 & 13 & 3 & 17 \\
\cline { 2 - 6 } & Netral & 3 & 2 & 11 & 16 \\
\hline \multicolumn{2}{|c|}{ TOTAL } & 16 & 16 & 18 & 50 \\
\hline
\end{tabular}

Hasil Perhitungan recall yang didapat dari pengujian terhadap data uji yang telah dilakukan masing-masing sebesar negatif $70,59 \%$, positif $76,47 \%$ dan Netral 68,75 dengan total recall keseluruhan dari data uji sebanyak 50 dan hasil prediksi benar sebanyak 36 didapatkan recall sebesar $72 \%$ dapat dilihat pada Tabel 8 .

TABEL VIII

HASIL PERHITUNGAN RECALL DATA UJI

\begin{tabular}{|c|c|c|c|}
\hline Kelas & Data Benar & Kelas Data Uji & Recall \\
\hline Negatif & 12 & 17 & $70,59 \%$ \\
\hline Positif & 13 & 17 & $76,47 \%$ \\
\hline Netral & 11 & 16 & $68,75 \%$ \\
\hline
\end{tabular}

Perhitungan precission dari data uji yang telah terprediksi oleh sistem yang telah dibuat pada Tabel 9, dimana hasil didapatkan masing-masing negatif $75 \%$, positif $81,25 \%$ dan netral $61,12 \%$ dengan total keseluruhan precission dengan data uji sebanyak 50 dan data yang terprediksi benar sebanyak 36 didapatkan nilai precission sebesar $72 \%$.
TABEL IX

HASIL PERHITUNGAN PRECISSION DATA UJI

\begin{tabular}{|c|c|c|c|}
\hline Kelas & Data Benar & Jumlah Prediksi & Precission \\
\hline Negatif & 12 & 16 & $75 \%$ \\
\hline Positif & 13 & 16 & $81,25 \%$ \\
\hline Netral & 11 & 18 & $61,12 \%$ \\
\hline Total & 36 & 50 & $72 \%$ \\
\hline
\end{tabular}

Sekenario juga dilakukan untuk melihat pengaruh dataset terhadap hasil akurasi yang diperoleh pada pengujian ini dengan menguji data uji dengan beberapa kali proses pelatihan dimana data uji masing masing perkategori berturut-turut dengan jumlah data latih yang sama yaitu sebanyak 50 dan skenario pengujian pertama dengan data latih masing-masing kelas kategori sebanyak 150 didapatkan akurasi sebesar 72\%, skenario kedua dengan data latih sebanyak 100 masing-masing kelas kategori didapatkan akurasi sebesar $66 \%$ dan skenario ketiga dengan data latih sebanyak 50 masing-masing kelas kategori didapatkan akurasi sebesar 52\%. Hasil akurasi dari skenario pengujian yang telah dilakukan dapat dilihat pada Tabel 10.

TABEL $X$

HASIL PENGUJIAN

\begin{tabular}{|c|c|c|c|c|}
\hline \multicolumn{3}{|c|}{ Data Latih } & \multirow{2}{*}{$\begin{array}{c}\text { Data } \\
\text { Uji }\end{array}$} & Akurasi \\
\cline { 1 - 3 } Positif & Negatif & Netral & & \\
\hline 150 & 150 & 150 & 50 & $72 \%$ \\
\hline 100 & 100 & 100 & 50 & $66 \%$ \\
\hline 50 & 50 & 50 & 50 & $52 \%$ \\
\hline
\end{tabular}

\section{E. Analisis Hasil Pengujian}

Analisis hasil pengujian dilakukan untuk mengetahui apakah implementasi yang dibuat dapat mengklasifikasi tweet tentang pendapat masyarakat terhadap pembangunan Kota Pontianak secara otomatis. Analisis pengujian dilakukan untuk guna mengevaluasi kinerja sistem dalam klasifikasi.

Dari hasil pengujian didapatkan bahwa pengujian yang dilakukan dapat melakukan klasifikasi tweet secara otomatis dengan memanfaatkan twitter API untuk mendapatkan data tweet agar dapat dilakukan proses klasifikasi secara otomatis.

Perbandingan dataset yang dilakukan yaitu data latih sebanyak 450 dan data uji sebanyak 50 dengan metode klasikasi nä̈ve bayes dan kategori kelas klasifikasi ke dalam tiga (3) kelas yaitu positif, negatif dan netral. Hasil pengujian pengklasifikasian dengan metode nä̈ve bayes didapatkan akurasi sebesar $72 \%$, precisson $72 \%$ dan recall sebesar $72 \%$. Diketahui juga dari pengujian yang telah dilakukan bahwa jumlah data latih mempengaruhi akurasi dalam pengklasifikasian.

\section{KESIMPULAN}

Adapun kesimpulan dari penelitian yang telah dilakukan adalah bahwa Pengujian yang dilakukan dapat mengklasifikasikan data tweet ke dalam sentimen positif, negatif atau netral secara otomatis. Jumlah data latih 
mempengaruhi performasi klasifikasi sentimen beserta akurasinya. Metode klasifikasi naïve bayes dengan sekenario dataset, 450 data latih dan 50 data uji menghasilkan akurasi sebesar $72 \%$, recall $72 \%$ dan precission $72 \%$.

Beberapa hal yang sarankan yaitu penambahan data latih dalam meningkatkan ketepatan pengkategorian data tweet, dan untuk menangani klasifikasi dapat menggunakan metode lain selain metode klasifikasi naïve bayes seperti metode SVM.

\section{DAFTAR PUSTAKA}

[1] A. V. Sudiantoro and E. Zuliarso, "Analisis Sentimen Twitter Menggunakan Text Mining Dengan Algoritma Naive Bayes Classifier," Pros. SINTAK 2018, 2018.

[2] [2] I. F. Rozi, S. H. Pramono, and E. A. Dahlan, "Implementasi Opinion Mining ( Analisis Sentimen ) untuk Ekstraksi Data Opini Publik pada Perguruan Tinggi," Electr. Power, Electron. Commun. Control. Informatics Semin., 2012.

[3] [3] J. Jotheeswaran and Y. S. Kumaraswamy, "Opinion Mining Using Decision Tree Based Feature Selection Through Manhattan Hierarchical Cluster Measure," J. Theor. Appl. Inf. Technol., 2013.

[4] [4] B. U. Manalu, "Analisis Sentimen pada Twitter Menggunakan Text Mining Skripsi Boy Utomo Manalu," Teknol. Inf. Fak. Ilk. UNSUT, 2014.

[5] [5] Falahah and D. Dwiki Adriadi Nur, "Pengembangan Aplikasi Sentiment Analysis Menggunakan Metode Naïve Bayes (Studi Kasus Sentiment Analysis dari media Twitter)," Semin. Nas. Sist. Inf. Indones., 2015.

[6] [6] S. Adi, "Perancangan Klasifikasi Tweet Berdasarkan Sentimen dan Fitur Calon Gubernur DKI Jakarta 2017," J. Inform. Pelita Nusant., vol. 3, no. 1, 2018.

[7] [7] D. Pakpahan and H. Widyastuti, "Aplikasi Opinion Mining dengan Algoritma Naïve Bayes untuk Menilai Berita Online," $J$. Integr., 2014.

[8] [8] E. E. Pratama and B. R. Trilaksono, "Klasifikasi Topik Keluhan Pelanggan Berdasarkan Tweet dengan Menggunakan Penggabungan Feature Hasil Ekstraksi pada Metode Support Vector Machine (SVM)," J. Edukasi dan Penelit. Inform., 2015.

[9] [9] F. Z. Tala, "A Study of Stemming Effects on Information Retrieval in Bahasa Indonesia," M.Sc. Thesis, Append. D, 2003.

[10] [10] A. F. Hidayatullah and M. R. Ma'arif, "Penerapan Text Mining dalam Klasifikasi Judul Skripsi,”Semin. Nas. Apl. Teknol. Inf. Agustus, 2016.

[11] [11] A. Pramono, R. Indriati, and A. Nugroho, "Sentiment Analysis Tokoh Politik Pada Twitter," Semin. Nas. Inov. Teknol. UN PGRI Kediri, 22 Februari 2017, 2017.

[12] [12]B. Kurniawan, S. Effendi, and O. S. Sitompul, "Klasifikasi Konten Berita dengan Metode Text Mining," J. Dunia Teknol. Inf., 2012.

[13] [13] N. W. S. Saraswati, "Text Mining dengan Metode Naïve Bayes Classifier dan Support Vector Machines untuk Sentiment Analysis," 2011.

[14] [14] A. Aprilianti P, "Sentiment Analysis dengan Naive Bayes untuk Melihat Persepsi Masyarakat Terhadap Batik pada Jejaring Sosial Twitter," in Seminar Nasional Matematika dan Pendidikan Matematika UMS Tahun 2015, 2015.

[15] [15]D. Novitasari, "Perbandingan Algoritma Stemming Porter dengan Arifin Setiono untuk Menentukan Tingkat Ketepatan Kata Dasar," STRING (Satuan Tulisan Ris. dan Inov. Teknol., 2017. 